\title{
A Review of Precision Fertilization Research
}

\author{
Can Chen ${ }^{1,2}$, Jianjun Pan ${ }^{1}$, Shu Kee Lam ${ }^{2}$ \\ (1 College of Resources and Environmental Sciences, Nanjing Agricultural University, Nanjing 210095 \\ China) \\ (2 Melbourne School of Land and Environment, the University of Melbourne, Victoria 3010, Australia)
}

\begin{abstract}
Precision agriculture plays an important role in sustainable development. Precision fertilization is the core of this field. Three methods of precision fertilization are introduced in this paper. They are: testing soil for formulated fertilization technology, decision support system and expert decision support system. Their development situations are also examined. Some suggestions in the agriculture sustainable development are also provided. The review summarized that $3 \mathrm{~S}$ technology will become the main data source in the decision support system and in development process of expert decision support system. The MIII technology can raise the soil testing efficiency. The development of precision fertilization has a great utility in the agriculture sustainable development.
\end{abstract}

Keywords Precision fertilization; Testing soil for formulated fertilization technology; Decision support system; Expert decision support system

\section{Introduction}

Human activities such as the application of fertilizer have led to increased levels of $\mathrm{N}$ and $\mathrm{P}$ in the atmosphere, as well as in most ecosystems on Earth(Liu et al. 2010). Balancing the trade-off between environmental quality and crop yield is an ongoing problem (Chandrajith et al. 2010). Precision agriculture is the hot research field in international agriculture science (Hu et al. 2005). Precision agriculture combines existing agriculture production measures with high-tech and new technology (Jess 2004). It also plays an important role in the information agriculture field and ensures sustainable agricultural development. Precision agriculture includes many aspects, for example, fertilization decision, irrigation water control, crop planting density, etc. (Peng et al. 2002; Liu et al. 2006). The main core of precision fertilization decision is in the precision agriculture field. The original precision fertilization can be traced to the method of the site-specific crop management (SSCM) (He et al. 2007; Zhao et al. 2005). Precision fertilization emphasizes that farmers should use the various fertilization methods, fertilizer species and application rates according to the different types of soil, weather conditions and other factors (Peng et al. 1996). The general research procedures of precision agriculture include: (1) Collecting the spatial information of the soil nutrients and the crop yield; (2) Analyzing the crop yield limiting factors and control factors; (3) Developing the fertilization model; (4) Determining the fertilization prescription; (5) Evaluating fertilization prescription (Wakabayashi et al. 1986; Owens 1981). Precision fertilization can be classified to three technology methods: testing soil for formulated fertilization technology, fertilization decision support system and expert decision support system. Therefore, the objective of this work was to introduce these three methods and their research progress, and to bring forward an opinion of the precision fertilization technology development.

\section{Testing soil for formulated fertilization technology}

\section{Introduction}

The purpose of soil testing for formulated fertilization technology is to determine the soil nutrients present and provide appropriate fertilization methods (Dowdle et al. 1988). The rationale of this approach is that crops can assimilate the different kinds of nutrient based on the specific soil conditions.

A Project Funded by “ Department of Agriculture, Forestry and Fisheries and Australian Research Council” and "A Project Funded by the Priority Academic Program Development of Jiangsu Higher Education Institutions" (PAPD).

* Corresponding author. E-mail address: chencan2010203025@163.com(C. Chen), Tel: +61 30452210913 
This method can be used to balance the nitrogen, phosphorus and potassium, organic and mineral nutrients, macro- and trace elements (Havlin et al. 1994; Zhu et al. 1992). Testing soil for formulated fertilization technology also can maintain the soil fertility level, decrease nutrient loss, and reduce environmental pollution (Dalias et al. 2002; Hadas et al. 1983). Therefore, it is the major core technology in a scientific fertilization system. An overview of testing soil for formulated fertilization is shown in Fig. 1.

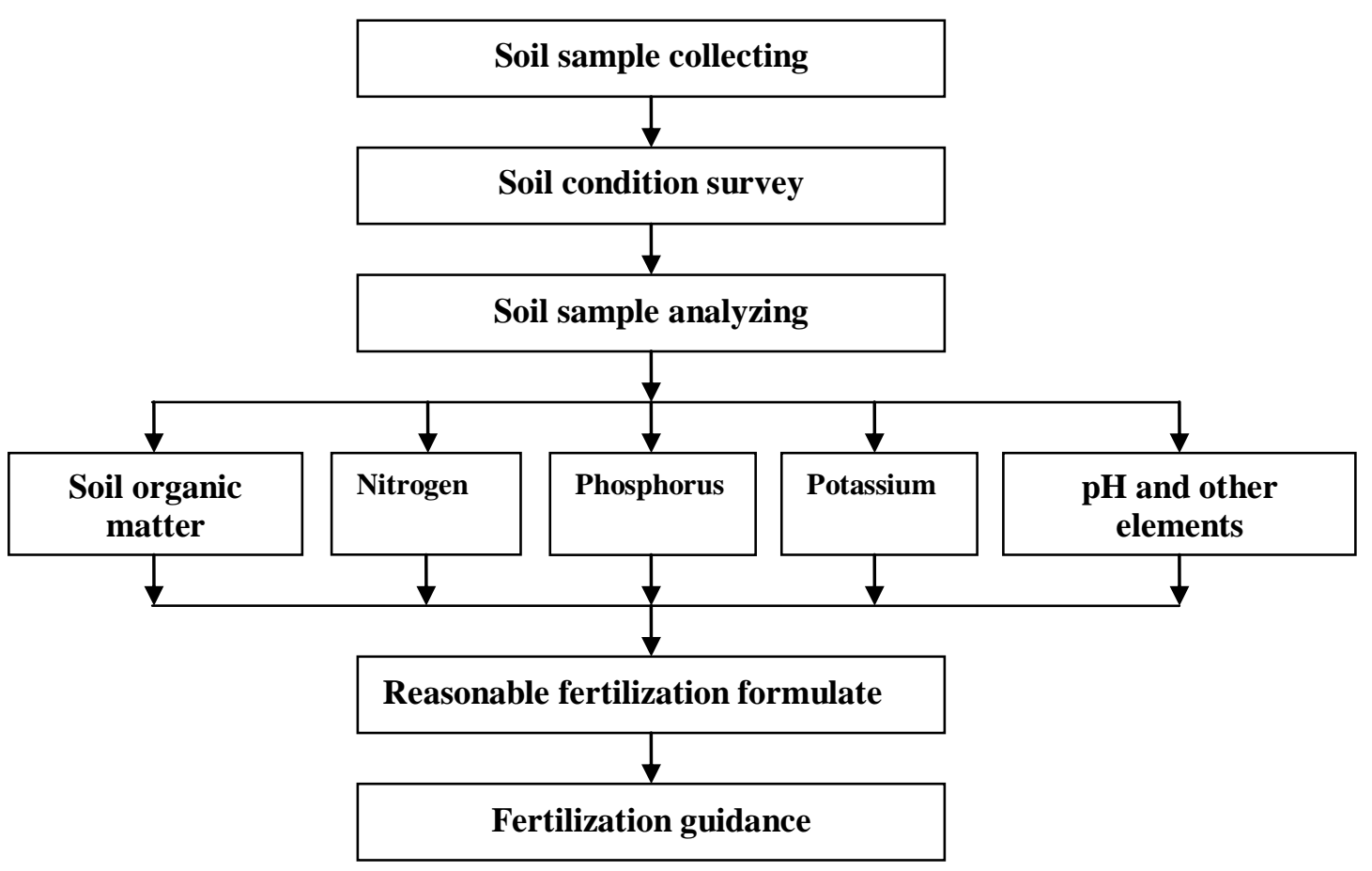

Fig. 1 Overview of testing soil for formulated fertilization

Soil testing methods

Soil testing methods play an important role in the testing soil for formulated fertilization technology. It will determine the fertilization formulate directly(Di et al. 2012). Among the traditional soil testing methods, the semi-micro kjeldahl method is used in nitrogen testing. The hydrofluoric acid-perchloric acid- Molybdenum antimony - colorimetric method, $\mathrm{H}_{2} \mathrm{SO}_{4}-\mathrm{HCl}$ method (Mehlich method), $\mathrm{NH}_{4} \mathrm{~F}-\mathrm{HCl}$ method (Bray method) and $\mathrm{NaHCO}_{3}$ method (Olsen method) etc. are used for phosphorus testing. Phosphorus also can be tested by plasma-optical emission spectrometry method (ICP-OES, OPTIMA 5300DV, Perkin Elmer) (Wang 2013). The hydrofluoric acid-perchloric acid- flame photometric method, neutral $\mathrm{NH}_{4} \mathrm{OAc}$ method and $\mathrm{H}_{2} \mathrm{SO}_{4}-\mathrm{HCl}$ with $\mathrm{NaOAc}$ method (Morgan method) are used for Potassium testing.

Fertilization methods

The mainstream fertilization method in the testing soil for formulated fertilization technology is nutrient abundance of ectrodactyly standard method, nutrient balance method and nutrition diagnosis method etc (Gordillo et al. 1997).

Nutrient abundance of ectrodactyly standard method

The main output of this method is "sufficient nutrient level". In other words, when the soil nutrient level is higher than the output value, additional fertilizer will not increase production. When the soil nutrient 
level is lower than the output value, farmers must apply a certain amount of fertilizer (Thomsen et al. 2000). In general, this method is used to apply phosphorus and potassium fertilizers and to increase the amounts of the trace elements.

Nutrient balance method

This method uses soil nutrient testing to calculate the soil fertility reservoir and to determine the fertilizer application rate. The main object of this method is "maintain standpoint". This is because the soil has a shock-absorbing capacity due to the soil nutrient dynamics. The amount of nitrogen that can be supplied by the soil reservoir is very difficult to calculate directly (Dancer et al. 1973). Researchers must use a "correction index" to adjust the estimated soil nutrient supply though experimentation. However, the variation of the correction index is very large and very difficult to determine accurately. Therefore, the correction index has statistical significance only when the soil nutrient test values and the crop yield have significant relationships. If there are no relationships between test values and the crop yield, the soil test values will not be significant (Griffin et al. 2000).

Nutrition diagnosis method

The crop nutrition diagnosis method is a fertilization technology based on the plant nutrient chemistry. The nutrition in the crop is the comprehensive reaction between soil nutrient supply and the nutrition which the crops need (Honeycutt et al. 1991). This technology can be classified to Tissue fluid velocity measurement and Plant tissue nutrient diagnosis technology index critical value. They have a wide range of application in the world (Honeycutt et al. 1993).

\section{Decision support system(DSS)}

\section{Introduction}

Decision support system is a computer application system, which can assist the decision maker to make the semi-structure or de-structuring decision, analyze the problem, develop a model and simulate the decision process and formulate environment. It also can transfer all kinds of information resource and analysis tool to the users' need(Tian et al. 2004). Decision support system use can raise the standard and quality of strategic decisions.

The character and structure of the agriculture decision support system

Agriculture decision support system integrates artificial intelligence with computer technology used in the agricultural field. It can make decisions based on models, weather conditions, crop species, fertilizer and soil types, etc.. The agriculture decision support system plays an important role in the agriculture information system. It is widely used in crop production management, irrigation, fertilization and crop species choice etc(Wang 1994).

Agriculture decision support system consists of four parts: data, model, reasoning and human-computer interaction (Xu 1990). A database is used to manage the data in the system. Model is operated by the model base and the model management system. Reasoning part is made up of the knowledge base, knowledge base management system and an inference engine. Human-computer interaction can receive and examine the request from users', transfer the software inside the system and print the decision report(Fig.2). Briefly, agriculture decision support system colligates the model running, data transfer and knowledge reasoning, solving the decision problem very effectively (Xie et al. 1996). 


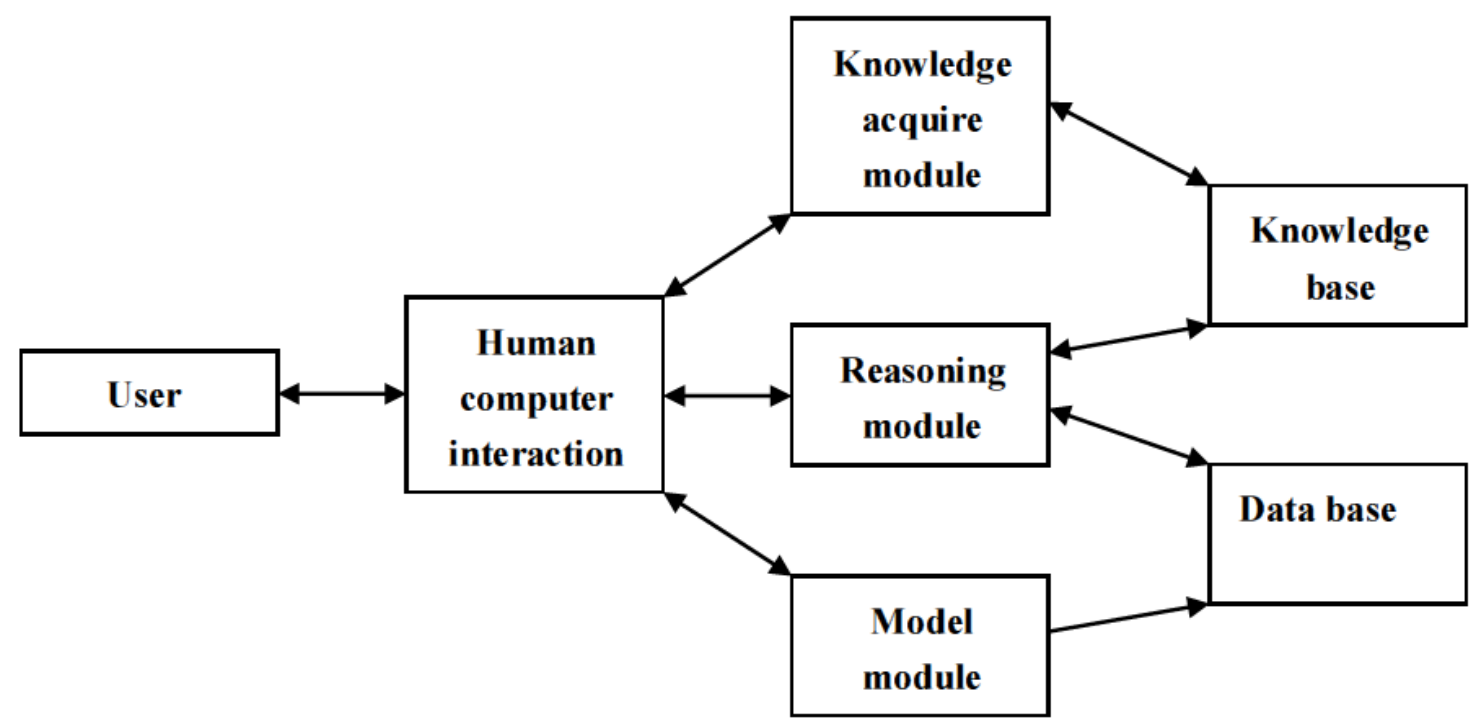

Fig.2 The structure of agriculture decision support system

The development of Agriculture decision support system

The information technology began to be used in the agriculture in the 1960s. DE WTI used the advanced high level computer language to simulate the geometry optical character and physiological process of maize leaf in 1965. He also developed the first agriculture computer model "ELCROS" to simulate the carbon balance(Xu 2000).

The concept of decision support system (DSS) had been mentioned. In 1980s, Sprague thought that decision support system should have three parts: human-computer interaction part, data part and model part. Defining the basic composition of decision support systems pushed forward the decision support system development (Tian et al. 2002).

In the end of 1980s and beginning of 1990s, the decision support system was combined with expert system (ES) to produce the intelligent decision support system (IDSS) (Tian et al. 2004). IDSS had advantage of both ES and DSS (Wang et al. 2002). ES could analyze qualitative problem though knowledge reasoning pattern and DSS could analyze quantitative problem though model calculation. IDSS is the new stage of the DSS development.

Data Warehouse (DW), On-Line Analysis Processing (OLAP) and Data Mining (DM) became the new concepts in decision support system in the middle 1990s. Thus the IDSS has been called "traditional" decision support system (Wang 1990). The characteristics of new decision support system are that it can derive auxiliary decision-making information and knowledge from the data. This is different from the traditional decision support system, which used model and knowledge to assist the decision (Wang 1995). So the auxiliary decision-making method is the major difference between traditional and new decision support systems.

Because of the popularity of Internet, decision support systems have been networked. Decision support system's decision resources (for example, data resource, model resource, knowledge resource) will become shared resources in the internet through the network server. Therefore the internet environment of decision support system will be the main topic in the future research (Wang et al. 2003; Turban et al. 2004; Wang et al. 2004 ).

\section{Examples}

\section{DéciBlé}

The DéciBlé software package has been developed as an aid for designing and appraising crop strategic planning by means of simulation in France(Chatelin et al. 2005). It can be used to simulate the 
consequences for technical operations and crop production of a set of decision rules over a wide range of possible contexts (regions, year-to-year weather variation, fields, etc.) (Attonaty et al. 1999). The DéciBlé has two core modules: a decision model and a crop model. The decision model module is used to represent the decision rules through a specific formalization and generate the operations for each context. The crop model is a set of modules simulating plant development, crop environment and yield accumulation implied by these operations in this context through the generation of loss functions or risk estimates (Moghaddas et al. 2013). The crop model has a specific "nitrogen" module which can be used to generate loss functions when nitrogen is a limiting factor for yield. It also can use the balance sheet method to assess the available nitrogen from the fertilizer application (Hammer et al. 2002). DéciBlé believes that the mineral $\mathrm{N}$ may be lost under conditions of leaching and/or non-optimum uptake; it uses Burns' simplified equation to calculate mineral $\mathrm{N}$ leaching and uses experimental data on nitrogen uptake efficiency and the agronomic diagnosis of uptake deficits to estimate the non-optimum uptake condition. Finally, the DéciBlé must be calibrated using experimental site data for the specific region to adjust the system's parameters.

\section{Land use system and evaluate(LUSE)}

LUSE is a decision support system to determine the rural land use allocation, especially land planted to agroforestry crops, in Spain. The main methods which develop this system are a variety of multi-objective linear programming methods (Inés et al. 2007). LUSE has several analytical modules. The first module is used to estimate the optimal sampling set by using the weighting method and the constraint method. The second of LUSE's analytical module implements goal programming. LUSE's third analytical module allows the user to explore the Pareto-optimal set interactively by means of two different approaches. The first is the STEP method, in which at each step other than the first, what is essentially a goal-programming solution obtained by the system in the previous step can be responded to by the user by relaxing the goal, or aspiration level, corresponding to one of the objectives so as to favour others in the second interactive method. The various objectives are successively optimized by means of single-objective optimizations. Unfortunately, LUSE can't estimate the nitrogen directly. But the rural land use allocation, especially the land allocated to agroforestry crops, can influence the nitrogen fertilizer efficiency indirectly.

\section{HydroLOGIC}

As a decision support system, HydroLOGIC aims to optimize cotton yield and water use for individual fields in Australia by integrating knowledge of crop physiology, agronomy, available water resources, soil physical properties, and climate. The main core of the HydroLOGIC is the cotton crop simulation model (OZCOT), which can be used to simulate the daily irrigation. The data required include observation data, climate data, alternative irrigation management scenarios for each season, and so on. HydroLOGIC has four components: soil profile, climate and weather, crop observations and scenario generator. Crop observation includes irrigation events, leaf area index, nitrogen applications, fruit counts and soil moisture. Nitrogen applications is a sub-module, where a crop receives a side-dressing of nitrogen post-sowing. This event may be recorded and used to update the crop nitrogen balance in OZCOT. The HydroLOGIC interface was developed in Microsoft_FoxPro_version 9.0, which allowed an object orientated $\mathrm{N}$-tiered development methodology using a fast desktop database engine with royalty free distribution. HydroLOGIC has been widely used in the Australia field irrigation research (Richards et al. 2008).

\section{MODAM}

MODAM is developed for the analysis of interdependencies between economic and ecological objectives in agricultural land use. The main core of MODAM is multiple criteria linear programming model which is hierarchically linked to several databases and a Geographical Information System (GIS) module. The data which is required by the system is managed by the professional 
database -LP-generator. "LP-generator" both automatically builds up the linear programming (LP) spread sheet and transfers all essential data to a comparative static-optimisation LP-model. The "LP-generator" also processes the output data of the optimization calculations and edits data for GIS-application. MODAM allows the calculation of a large number of different types of scenarios (Kachele et al. 2002).

\section{International Consortium for Agricultural Systems Applications (ICASA)}

ICASA is an international collaborative network, which aims to overcome various barriers, so that models and other systems application tools are scientifically-sound, widely available, and effective in supporting agriculture and natural resource management decisions (Bouma et al. 2001). There are four main guidelines: 1 . the need for high quality data for developing and evaluating crop models; 2 . the difficulty of obtaining crop model inputs across space and time for real world problems; 3.the time and other resources necessary to develop, validate, document, and maintain crop models; and 4 . the focus on simulating potential and water-limited yield with continuing limitations of models to simulate actual yield in farmers' fields.

ICASA's goals is to promote co-operation among different groups who are developing and applying agricultural systems models to address practical issues so that duplication of effort will be reduced through the use of existing models or components and compatible data. ICASA's other aim is to help guide efforts to define these standards so that software can be developed or adopted to facilitate their widespread adoption and use. Therefore, ICASA is the medium for accomplishing the researchers' purpose though the network (Bouma et al. 2001).

\section{PCYield}

PCYield was designed under the auspices of the United Soybean Board (USB), in cooperation with Weather Services International (WSI Corp.) of Billerica, MA and, through them, with a national chain of agricultural input and service providers (Welch et al. 2002). It directly supports a narrow range of decisions with a simple user interface, yet incorporates the key elements of more complex decision support systems, including (1) the CROPGRO-Soybean model, (2) field-specific data management, (3) internet access to real-time weather data, (4) production risk indicators, and (5) graphical output displays. The sections follow describe the program and the history of its development and commercialization. PCYield can answer two specific questions at any point in the growing season: (1) "What yield range might be expected?" and (2) "What happens if irrigation is withheld for a time and the weather stays dry?" Answers to these two questions, if used properly, can assist with cultivar selection, planting date determination, replanting decisions, irrigation scheduling, marketing, and estimating the effects of abnormal weather, especially drought. In this context, PCYield can be viewed as an example of software that combines university research, private sector activity, crop models, and Internet data delivery to meet producer needs(Welch et al. 2002).

\section{AgriSupport system}

AgriSupport system is used to make farm planning and technical advice systems help farmers to optimize their resources according to business prospects, and manage the production risk in the manner best suited to their interests (Recio et al. 2003). The system includes three elements: A model that is composed of a series of abstractions to structure agriculture productive process elements and specialized algorithms that, working over them, perform the planning and the analysis of a farm using different calculation paths in function of the freedom of the problem variables. A system that is composed of a series of software tools to assist in the development of DSSs using the above models and algorithms. A methodology guides in the analysis of a problem in agriculture advising and the design of DSS to support it. The system also must take into account all the agricultural activities of the farm to decide on the minimum requirements in terms of machinery, and labored., for viable operation. The activities must include field work and field operation (Recio et al. 2003). 


\section{NuMaSS}

The Nutrient Management Support System (NuMaSS) software enables the evaluation of soil characteristics related to organic matter (OM) including carbon, nitrogen, phosphorus, moisture content, clay content and $\mathrm{CaCO}_{3}$, etc. (Walker et al. 2009). The system includes acidity, phosphorus, and nitrogen modules. Each module has four components: diagnosis, prediction, economic evaluation and recommendation. These four components represent different steps in the decision-making process often which is seen in experts making fertilizer application decisions. The system also has an economic module. It includes: (1) a statistical analysis of on-farm experimental data that is the raw material for identifying the productivity effects of NuMaSS treatments, (2) a partial budget of the statistically significant and economically dominant NuMaSS treatment, and (3) a project appraisal of the regional liming program. Finally, the farmer fertilizer-use module can compare to three treatment benchmarks in the on-farm experiments: (1) the rate simulating the farmer practice, (2) the recommended regional intensity of application, and (3) the NuMaSS recommendation that depended on soil testing (Walker et al. 2009).

\section{Expert decision support system}

\section{Introduction}

Expert decision support system (EDSS) combines the traditional decision support system with the expert system (Corson et al. 2007). This system can simulate the experts' knowledge and provide consultation and assistance functions which runs up to the expert level to the decision maker. The decision-making is mostly applied to solving environment problem (Sun et al. 2006).

The characteristics of expert decision support system include: (1) Allowing the decision-maker to join the system decision process from the start to the end. (2) The system has the study ability. The ability of decision-maker and decision support system can all be enhanced from practical operations. (3) The system integrates the knowledge reasoning and numeric calculation. Expert decision support systems have much stronger decision ability than the traditional decision support system. (4) The system develops the universal logical composition and physical composition. So it has a wide field of service. Thus, it remains suitable when the environment and decision methods change.

\section{Examples}

DAIRYPRO is a combination of decision support and expert system consisting of two modules (Kerr et al. 1999). The system is designed to help dairy farmers in northern Australia to make strategic decisions about their farm. The system includes two modules- FARMPROD and FARM- DIAG. The FARMPROD is developed by using a combination of the output from statistical models and the rules of thumb obtained from the knowledge of an expert in dairy farming in northern Australia. The FARMDIAG is developed as a diagnostic tool, asking farmers to provide key input and output parameters on four pre-defined programs in their dairy farm. DAIRYPRO has a fertilizer component which is incorporated in each pasture or crop response rate. As its influence is reflected in the production expected from well managed pastures with adequate levels of fertilizer. DAIRYPRO is considered to be a diagnostic EDSS, which is able to identify gross disorders within a dairy farm. It is an umbrella program that is able to identify problems with the general level of efficiency of the farm under study(Kerr et al. 1999).

\section{Conclusion}

With the rapid development of Internet technology, precision fertilization is expanding from the traditional laboratory proofing to the decision support system. But there are still some problems. First of all, although the decision support system and expert decision support system can very conveniently 
make recommendations for fertilization, there isn't a uniform and convincing evaluation methodology to validate the simulated result. Secondly, the decision support system and expert decision support system needs a mass of field experimental data. Therefore, obtaining these data quickly and efficiently is a big challenge. Finally, tradition laboratory proofing is the best way to get the soil nutrient data. So it is important to find a method, which can do the rapid testing soil for formulated fertilization.

GIS, RS and GPS technology ( $3 \mathrm{~S}$ technology) can rapidly get the spatial data at the large scale and area. They can also apply the spectrum technology to interpret plant nutrition status data. Therefore, $3 \mathrm{~S}$ technology will become the main data source in the decision support system and in the development process of expert decision support systems. As a soil testing method development, MIII technology was used in popularization and application world-wide. The extracting reagent of MIII method can extract multi-elements in one time. Then researchers can use Inductive Coupled Plasma Emission Spectrometer (ICP) to test the samples at the same time. The precision of results is very high. Thus MIII technology can improve soil testing efficiency.

Precision fertilization methods can be very helpful in solving the problem of low fertilization efficiency. The development of precision fertilization has a great impact in agricultural sustainable development.

Acknowledgements The authors thank Dr. Christopher Ogden (Cornell Medical College in Qatar) for his check of English and comments on this paper. We also wish to express our thanks to anonymous reviewers for providing useful comments to improve the paper. This study is jointly supported by funding from " Department of Agriculture, Forestry and Fisheries and Australian Research Council", and " The Priority Academic Program Development of Jiangsu Higher Education Institutions" (PAPD) .

\section{Reference}

Attonaty JM, Chatelin MH, Garcia F (1999) Interactive simulation modeling in farm decision making. Comput. Computers and Electronics in Agriculture 22:157-170

Bouma J, Jones JW (2001) An international collaborative network for agricultural systems applications (ICASA). Agricultural Systems 70:355-368

Chandrajith R, Seneviratna S, Wickramaarachchi K, Attanayake T, Aturaliya TNC, Dissanayake CB (2010) Natural radionuclides and trace elements in rice field soils in relation to fertilizer application: study of a chronic kidney disease area in Sri Lanka. Environmental Earth Sciences, 60:193-201

Chatelin MH, Aubry C, Poussin JC, Meynard JM, Masse J, Verjux N, Ph. Gate, Le Bris Le (2005) DéciBlé, a software package for wheat crop management simulation. Agricultural Systems 83:77-99

Corson, MS, Rotz CA, Skinner RH, Sanderson MA (2007) Adaptation and evaluation of the integrated farm system model to simulate temperate multiple-species pastures. Agricultural Systems 94:502-508

Dalias P, Anderson JM, Bottner P, Coûteaux MM (2002) Temperature responses of net nitrogen mineralization and nitrification in conifer forest soils incubated under standard laboratory conditions. Soil Biology and Biochemistry 34:691-701

Dancer WS, Peterson LA, Chesters G (1973) Ammonification and nitrification of $\mathrm{N}$ as influenced by soil pH and previous N treatments. Soil Science Society of America Proceeding 37:67-69

Di Lorenzo T; Brilli M Del Tosto D, Galassi DMP, Petitta M (2012) Nitrate source and fate at the catchment scale of the Vibrata River and aquifer (central Italy): an analysis by integrating component approaches and nitrogen isotopes. Environmental Earth Sciences, 67:2383-2398

Dowdle S, Potrch S (1988) A systematic approach for determining soil nutrient constrains and establishing balanced fertilizer recommendations for sustained high yield. Proceedings of the International Symposium on Balanced Fertilization 20:243-251.

Gordillo RM, Cabrera ML (1997) Mineralizable nitrogen in broiler litter II. Effect of selected soil characteristics. Journal of Environmental Quality 26:1679-1686

Griffin T S, Honeycutt CW (2000) Using growing degree days to predict nitrogen availability from livestock manures. Soil Science Society of America Journal 64:1876-1882

Hadas A, Bar-Yosef B, Davidov S, Sofer M (1983) Effect of pelleting, temperature,and soil type on mineral nitrogen release from poultry and dairy manures. Soil Science Society of America Journal 47:1129-1133

Havlin JL, Jacobsen JS (1994) Soil Testing: Prospects for Improving Nutrient Recommendations(Ed.). Soil Science Society of America (SSSA)Special Publication Number 40, Madison, Wisconsin, USA

Hammer GL, Kropff MJ, Sinclair TR, Porter JR (2002) Future contributions of crop modeling from heuristics and supporting decision making to understanding genetic regulation and aiding crop improvement. European Journal of Agronomy 18:15-31

He F, Huang JL, Cui KH (2007) Effect of real time and site specific nitrogen managements on rice yield and quality. 
Scientia Agricultura Sinica 40:123-132(in Chinese)

Honeycutt CW, Potaro LJ, Halteman WA (1991) Predicting nitrate formation from soil, fertilizer, crop residue, and sludge with thermal units. Journal of Environmental Quality 20:850-856

Honeycutt CW, Potaro LJ, Avila KL, Halteman WA (1993) Residue quality, loading rate and soil-temperature relations with hairy vetch(viciavillosa roth)residue carbon, nitrogen and phosphorus mineralization. Biological Agriculture and Horticulture 9:181-199

Hu LJ, Li TL (2005) Questions and countermeasures in the development of precision agriculture. Journal of Shenyang Agricultural University (Social Sciences Edition) 400-402

Inés S, Rafael C (2007) LUSE, a decision support system for exploration of rural land use allocation: Application to the Terra Chá district of Galicia (N.W. Spain), Agricultural Systems 94:341-356

Jess LD (2004) A bird's eye view of precision agriculture. In: Precision Agriculture. Wageningen: Wageningen Academic Publish 2:8-10

Kachele H, Dabbert S (2002) An economic approach for a better understanding of conflicts between farmers and nature conservationists - an application of the decision support system MODAM to the Lower Odra Valley National Park. Agricultural Systems 74:241-255

Kerr DV, Cowan RT, Chaseling J (1999) DAIRYPRO- a knowledge-based decision support system for strategic planning on sub-tropical dairy farms. I. System description Agricultural Systems 59:245-255

Liu LJ, Xu W, Sang DZ (2006) Site specific nitrogen management increases fertilizer nitrogen use efficiency in rice. Acta Agronomica Sinica 987-994(in Chinese)

Liu DY, Song CC (2010) Effects of inorganic nitrogen and phosphorus enrichment on the emission of $\mathrm{N}_{2} \mathrm{O}$ from a freshwater marsh soil in Northeast China. Environmental Earth Sciences, 60:799-807

Moghaddas NH, Namaghi HH, Ghorbani H, Dahrazma B (2013) The effects of agricultural practice and land-use on the distribution and origin of some potentially toxic metals in the soils of Golestan province, Iran. Environmental Earth Sciences, 68:487-497

Owens LB(1981) Effects of nitrapyrin on nitrate movement in soil columns. Journal of Environment Quality 10:308-310

Peng SB, Huang JL, Zhong XH Bureshl R, Wittl C (2002) Research strategy in improving fertilizerr nitrogen use efficiency of irrigated rice in China. Scientia Agricultura Sinica 3:1095-1103(in Chinese)

Peng SB, Garcia FV, Laza RC, Sanico AL, Visperas RM, Cassman KG (1996) Increased N-use efficiency using a chlorophyll meter on high yielding irrigated rice. Field Crops Research 57:243-252

Recio B, Rubio F, Criado JA (2003) A decision support system for farm planning using AgriSupport II. Decision Support Systems 36:189-203

Richards QD, Bange MP, Johnston SB (2008) HydroLOGIC: An irrigation management system for Australian cotton. Agricultural Systems 98:40-49

Sun B, Yan H, Shi JP (2006) Development and application of fertilization decision-making supporting systems based on ComGIS. Transactions of the CSAE 34:75-79

Thomsen IK, Olesen JE (2000) C and N mineralization of composted and anaerobically stored ruminant manure in differently textured soils. Journal of Agricultural Science 135:151-159

Tian J, Wang Y, Li H (2004) Applications and development of DSS in China. Working Paper, Xian Jiaotong University

Tian J, Zhang P, Wang K, Wang Y (2004) Integrating experts' opinions using Delphi method. Chinese Journal of Systems Engineering Theory and Practice 28:57-62(in Chinese)

Tian Q, Ma J, Liu O (2002) A hybrid knowledge and model system for R\&D project selection. Expert Systems with Applications 23:265-271

Turban E, Zhou D, Ma J (2004) A group decision support approach to evaluating journals. Information and Management 他 42: 31-44.

Wakabayashi S, Matsubara H, Webster DA (1986) Primary sequence of a dimeric bacterial haemoglobin from Vitreoscilla. Nature 322:481-483

Walker T, Friday J, Casimero M, Dollentas R, Mataia A, Acda R, Yost R (2009) The early economic impact of a nutrient management decision support system (NuMaSS) on small farm households cultivating maize on acidic. upland soils in the Philippines, Agricultural Systems 101:162-172

Wang G, Lei Y, He J (2002) An interception guidance expert system for air combat decision. Journal of Air Force Engineering University 23:11-13(in Chinese)

Wang H(1994) The restraint constellation circling theory in decision-making. Chinese Soft Science 23: 25-27(in Chinese)

Wang KJ, Chien CF (2003) Designing an Internet-based group decision support system. Robotics and Computer-Integrated Manufacturing 19:65-77

Wang WL, Liang T, Wang LQ, Liu YF, Wang YZ, Zhang CS (2013) The effects of fertilizer applications on runoff loss of phosphorus. Environmental Earth Sciences 68:1313-1319

Wang X, Yu S, Huang G (2004) Land allocation based on integrated GIS-optimization modeling at a watershed level. Landscape and Urban Planning 66:61-74

Wang Y(1995) Systems Engineering, Mechanical Engineering Press, Beijing(in Chinese)

Wang Z (1990) Intelligent interface and integrated DSS, Decision Sciences and Systems Engineering, Science and Technology Press of China, Beijing(in Chinese) 
Welch SM, Jones JW, Brennan MW, Reeder G., Jacobson BM (2002) PCYield: model-based decision support for soybean production. Agricultural Systems 74:79-98

Xie K, Zhao J(1996) Research on framework of IDSS. Journal of Shanghai Jiaotong University 3:76-80(in Chinese)

$\mathrm{Xu}$ LD(2000) The contribution of systems science to information systems research. Systems Research and Behavioral Science 17:105-116

Xu J (1990) The country level overall development DSS. Decision Sciences and Systems Engineering, Science and Technology Press of China, Beijing(in Chinese)

Zhao C J, Xue X Z (2005) Progress of agricultural information technology. In: Proceedings of the 3rd International Symposium on Intelligent Information Technology in Agriculture. Beijing: China Agricultural Science and Technology Press 45:1-10(in Chinese)

Zhu Z L, Wen Q X (1992) Nitrogen in soils of China. Nanjing: Jiangsu Science and Technology Press(in Chinese) 


\section{University Library}

\section{- M M I E R R V A gateway to Melbourne's research publications}

Minerva Access is the Institutional Repository of The University of Melbourne

Author/s:

Chen, C;Pan, J;Lam, SK

Title:

A review of precision fertilization research

Date:

2014-05-01

Citation:

Chen, C., Pan, J. \& Lam, S. K. (2014). A review of precision fertilization research.

ENVIRONMENTAL EARTH SCIENCES, 71 (9), pp.4073-4080. https://doi.org/10.1007/ s12665-013-2792-2.

Persistent Link:

http://hdl.handle.net/11343/283291 